\title{
Danio rerio as a model for post-mortem interval estimation based on methylation levels
}

Rita Sabino Abrantes de Pina ( $\square$ rita.sabino.pina@gmail.com )

Universidade de Aveiro https://orcid.org/0000-0002-7358-5455

\section{Luís Souto}

Universidade de Aveiro

Helena Moreira

Universidade de Aveiro

\section{Research note}

Keywords: Post-mortem interval (PMI), Epigenetics, DNA methylation, Zebrafish, Real time PCR (q-PCR), High Resolution Melting (HRM)

Posted Date: October 31st, 2019

DOI: https://doi.org/10.21203/rs.2.16607/v1

License: (9) This work is licensed under a Creative Commons Attribution 4.0 International License. Read Full License 


\section{Abstract}

Objective The post-mortem interval (PMI) describes the period of time elapsed since death. A precise estimation of PMI has a strong impact in a crime investigation; however, it becomes a complex task due to the influence of intrinsic and extrinsic factors. There are several methods for PMI determination including pathological, biochemical and entomological. Those methodologies have low precision and several practical limitations leading to the emergence of genetic-molecular methods based on degradation of nucleic acids. DNA methylation is a sufficiently stable and time-related epigenetic modification, making it useful for the development of a method to determine PMI. Thus, the methylation levels of a model organism - zebrafish - were analysed since the moment of death, in order to contribute to create a robust model for the PMI estimation.

Results In this study, we evaluated the variation in global methylation levels and at the promoter region of EDARADD gene during 6 post-mortem intervals. An increase of global methylation levels in the initial post-mortem intervals was observed, followed by an abrupt decrease until $48 \mathrm{~h}$ post-mortem. Followed by the amplification of EDARADD's promoter region by q-PCR and HRM analysis, it was possible to differentiate samples according to relative PMI.

\section{Introduction}

A precise estimation of the time elapsed since death - post-mortem interval (PMI) - is one of the major focuses of investigation in forensic science because it allows the corroboration of witness statements, the restriction of the number of suspects and the confirmation of the veracity of their alibis [1]. However, it is a complex problem due to a plethora of factors that affect the process of post-mortem changes. Intrinsic factors include age, sex and physiological and pathological states of the victim. On the other hand, there are extrinsic factors like temperature, humidity and insect activity, which can affect the precise estimation of post-mortem interval. Traditional methods to estimate PMI are generally based on physiological changes such as algor mortis, livor mortis and rigor mortis, but those methods can only provide a rough estimation of PMI [2] [3]. Over the years, several molecular-genetic methods using nucleic acid degradation have been developed for the determination of post-mortem interval. Although those methods are very promising and the parameters analysed depend on the time since death, a new approach appears: the possibility to study the variation of DNA methylation levels to estimate PMI.

Methylation is a well-studied chemical modification of DNA, a molecule with high post-mortem stability proven by several authors [4]. DNA methylation consists in the addition of a methyl group to the fifth carbon of a cytosine $(5-\mathrm{mC})$ preceding a guanine $(\mathrm{CpG})$. The analysis of DNA methylation patterns is a methodology with enormous potential to estimate the $\mathrm{PMI}$, despite not being exploited currently.

In this study, we evaluated the global DNA methylation levels during PMI, as well as the variation of methylation levels at EDARADD gene promoter. For that purpose, a model organism was used-zebrafish 
-which permitted a homogeneous sampling, as well as the control of intrinsic and extrinsic factors that could affect the PMl estimation.

\section{Methods}

\section{Zebrafish Care}

Zebrafish (D. rerio) specimens from a culture established at the Department of Biology, University of Aveiro, were maintained in carbon-filtered water at $27.0 \pm 1^{\circ} \mathrm{C}$ under a $14: 10 \mathrm{~h}$ light/dark photoperiod cycle. Conductivity is kept at $800 \pm 50 \mu \mathrm{S}, \mathrm{pH}$ at $7.5 \pm 0.5$ and dissolved oxygen at $95 \%$ saturation. Adult fish were fed once daily with GEMMA 500, a commercially available artificial diet.

Sampling and Genomic DNA Extraction

Twelve healthy adult male zebrafishes at 8 months-old were killed by hypothermia induction. To avoid a heterogeneous sampling, all fish were weighed $(274,17 \pm 90,10 \mathrm{mg})$ and body size was registered $(3,13 \pm 0,26 \mathrm{~cm})$.

After death, they were randomly divided into a control group (PMI=0h) and five experimental groups $\left(P M I=1,4,24,48\right.$ and $72 \mathrm{~h}$ ) which were composed of two individuals. Specimens were kept at $4^{\circ} \mathrm{C}$ during the correspondent post-mortem time. Subsequently, whole fish samples were homogenised with liquid nitrogen and frozen at $-20^{\circ} \mathrm{C}$ until DNA extraction using modified CTAB method, according to the protocol described by Stefanova et al. (2013) [5]. DNA concentration was measured using Nanodrop $1000^{\mathrm{TM}}$ Spectrophotometer (Thermo Scientific).

Global DNA Methylation

Global DNA methylation was measured with the MethylFlash ${ }^{\text {TM }}$ Methylated DNA Kit - Colorimetric (Epigentek) following the manufacturer's protocol. The OD intensity of the colorimetric reaction was measured by a Biotek ELx800 plate reader (Winooski, VT, USA). The OD intensity of each sample was normalized to $100 \mathrm{ng}$ of DNA. The absolute quantification of cytosine methylation was calculated in twosteps: first, it was generated a standard curve and then, it was plotted the OD values versus the amount of positive controls at each concentration point, followed by determination of the slope (OD/ng) of the standard curve using linear regression. The cytosine methylation was calculated by using the formula: [(OD sample - OD negative control) / (slope $\times 2$ ] where 2 is a factor to normalize 5-methylcytosine in the positive control to $100 \%$. Cytosine methylation percentage was calculated according to: [(5-mC Amount (ng)) / (S)] $\times 100$; being 5-mC amount (ng) the value obtained by the formula above and $S$ the amount of DNA per sample. Each control was measured in duplicate and each post-mortem sample in triplicate. 
All statistical calculations were performed using Microsoft Excel (2010) and IBM Software Package for the Social Sciences (SPSS, IBM). The t-student's test was applied in order to find significant differences between pooled zebrafish measurements for each PMI.

Methylation at EDARADD gene promoter

1. Sodium Bisulphite Treatment

DNA methylation analysis was performed with bisulphite conversion, where non-methylated cytosines were converted in uracils keeping 5-methylcytosines intact. DNA bisulphite modification was performed using EZ DNA Methylation-Gold ${ }^{\mathrm{TM}}$ Kit (Zymo Research) following the manufacturer's recommendations.

\section{Amplification by q-PCR}

The amplification by q-PCR was performed for EDARADD gene promoter. In order to analyse EDARADD levels during PMI, a q-PCR array was carried out in $20 \mu \mathrm{L}$ volume and contained $10 \mu \mathrm{L}$ Xpert Fast SYBR (uni) (Grisp).), $0.3 \mu \mathrm{M}$ of forward and reverse primer (Table 1 ) and $1 \mu \mathrm{L}$ of the DNA template. Real Time PCR was carried on CFX96 ${ }^{\text {TM }}$ Real-Time PCR (Bio-Rad), with the following conditions: initial denaturation at $95^{\circ} \mathrm{C}$ for $3 \mathrm{~min}$, followed by 40 cycles at $95^{\circ} \mathrm{C}$ for $5 \mathrm{~s}, 30 \mathrm{~s}$ at the primer's specific annealing temperature and DNA extension at $72^{\circ} \mathrm{C}$ for 30 s.

Table 1: Information about primers for EDARADD gene promoter.

\begin{tabular}{|c|c|c|c|c|}
\hline $\begin{array}{c}\text { Gene } \\
\text { promoter }\end{array}$ & Primer & Sequence & Annealing Temperature $\left({ }^{\circ} \mathrm{C}\right)$ & Fragment size (bp) \\
\hline EDARADD & Forward & GGT AGA TTA AGA GGA AGT TTA TTT TTT TAT & \multirow{2}{*}{57} & 231 \\
\cline { 2 - 3 } & Reverse & AAT ACC TCT CCC CAT CTA TTT AAT C & & \\
\hline
\end{tabular}

High-resolution melting curve analysis

HRM was conducted immediately after amplification in the following conditions: increase in temperature from $65^{\circ} \mathrm{C}$ to $95^{\circ} \mathrm{C}$, with $0.5^{\circ} \mathrm{C}$ increment, each step with a 5 s hold. The HRM data was analysed using the Precision Melt Analysis ${ }^{T M}$ Software (Bio-rad).

\section{Results}

Quantification of global DNA methylation levels during PMI

After DNA extraction from the post-mortem samples of the whole fish, the levels of global methylation were measured. For control samples, 8 month-old zebrafish that were not submitted to any PMI, the 
methylation levels were around 3\%, the same value found in other study. [6]

Figure 1: Variation in DNA Methylation levels during PMI.

Regarding the variation of methylation between $0 \mathrm{~h}$ and $\mathrm{Th}$ after death, the levels did not undergo statistically significant changes, increasing only $0.35 \%$. As for the variation in methylation between $1 \mathrm{~h}$ and $4 \mathrm{~h}$ post-mortem, a statistically significant increase of $1.49 \%$ was observed. A statistical data shows this in more detail (see Additional File 1).

Between $4 \mathrm{~h}$ and $24 \mathrm{~h}$ after death, the results show a $0.76 \%$ decrease in methylation (Figure 1), however, it is not statistical significant. Comparing the variation in the amount of $5-\mathrm{mC}$ between 24 and 48 postmortem hours, the methylation level decreased about $1.75 \%$, reaching the lowest value recorded throughout the study (see Additional File 1).

Finally, regarding the interval between $48 \mathrm{~h}$ and $72 \mathrm{~h}$ post-mortem, the results show a marked increase $(3.45 \%)$ in the amount of methylated cytosines, reaching the highest value recorded at $72 \mathrm{~h}$ after death (see Additional File 1).

\section{Variation of methylation levels in EDARADD gene promoter}

After bisulphite treatment, the methylated status of the EDARADD gene promoter was evaluated by q-PCR followed by HRM analysis.

Table 2: Data obtained by HRM analysis for EDARADD gene promoter, according to PMI. 


\begin{tabular}{|c|c|c|c|c|}
\hline PMI (h) & Sample & Cluster & Melting temperature $\left({ }^{\circ} \mathrm{C}\right)$ & Percent confidence (\%) \\
\hline \multirow[t]{4}{*}{0} & ip0 & \multirow[t]{2}{*}{1} & \multirow[t]{4}{*}{72,5} & \multirow[t]{2}{*}{97,9} \\
\hline & ip0' & & & \\
\hline & ip0a & \multirow[t]{2}{*}{2} & & \multirow[t]{2}{*}{97,6} \\
\hline & ip0a' & & & \\
\hline \multirow[t]{4}{*}{1} & ip1 & \multirow[t]{2}{*}{1} & 72,5 & \multirow[t]{2}{*}{97,8} \\
\hline & ip1' & & 72 & \\
\hline & ip1a & \multirow[t]{2}{*}{5} & \multirow[t]{2}{*}{72,5} & \multirow[t]{2}{*}{98,0} \\
\hline & ip1a' & & & \\
\hline \multirow[t]{4}{*}{4} & ip4 & \multirow[t]{2}{*}{6} & \multirow[t]{3}{*}{72} & \multirow[t]{2}{*}{97,9} \\
\hline & ip4' & & & \\
\hline & ip4a & \multirow[t]{2}{*}{2} & & \multirow[t]{2}{*}{97,5} \\
\hline & ip4a' & & 72,5 & \\
\hline \multirow[t]{4}{*}{24} & ip24 & \multirow[t]{3}{*}{1} & \multirow[t]{3}{*}{72,5} & \multirow[t]{3}{*}{98,9} \\
\hline & ip24' & & & \\
\hline & ip24a & & & \\
\hline & ip24a' & 5 & 72 & 98,0 \\
\hline \multirow[t]{4}{*}{48} & ip48 & \multirow[t]{2}{*}{3} & \multirow[t]{4}{*}{72} & \multirow[t]{2}{*}{98,2} \\
\hline & ip48' & & & \\
\hline & ip48a & \multirow[t]{2}{*}{4} & & \multirow[t]{2}{*}{97,8} \\
\hline & ip48a' & & & \\
\hline \multirow[t]{4}{*}{72} & ip72 & \multirow[t]{4}{*}{7} & \multirow[t]{2}{*}{73,5} & \multirow[t]{2}{*}{97,7} \\
\hline & ip72' & & & \\
\hline & ip72a & & \multirow[t]{2}{*}{73} & \multirow[t]{2}{*}{98,7} \\
\hline & ip72a' & & & \\
\hline
\end{tabular}

As it can be seen in Table 2, samples were grouped in 7 different clusters and, in some cases, independently of the PMI to which they belonged. For example, the samples ip0 and ip0a, even belonging to the same PMI were assembled in cluster 1 and 2, respectively. The samples ip1, ip24 and ip24a were also assembled in cluster 1 , which means that there are no significant differences in melting curves that distinguish them. On the other hand, it was recorded that the samples corresponding to $\mathrm{PMl}=72 \mathrm{~h}$ were assembled in the same cluster, emphasizing their similarity.

\section{Discussion}


This study aimed to evaluate the variation of global and target gene promoter methylation levels over the time elapsed since death. The promoter region of EDARADD gene was selected for methylation analyses since it has been documented to be related to the human aging process [7]. The sampling of the study was composed by individuals of the same age in order to observe the variation of methylation levels in this promoter with the PMI. The results indicate an oscillation of methylation levels over the post-mortem interval both in overall methylation and at the promoter region of the EDARADD gene.

HRM analysis allowed to group the samples in different clusters, depending on the PMI. Initially, because it is an extremely sensitive approach, this technique is capable of distinguishing between samples within the same PMI. However, at longer PMIs, the distinction only occurs by the post-mortem interval, meaning that no differences between samples are considered.

Zebrafish was a successful model organism for post-mortem interval estimation, because it allowed a homogeneous sampling and the ability to control all extrinsic factors.

\section{Limitations}

In this study it was used 12 specimens. The next step is increase sampling using this PMI and, later includes longer PMI and other type of samples, namely specific tissue samples. Finally this methodology should be tested in other model organisms until is fully improved for application in criminal investigations.

\section{List Of Abbreviations}

PMI-post-mortem interval

EDARADD-EDAR-Associated Death Domain

q-PCR-Real time Polymerase Chain Reaction

HRM-High Resolution Melting

\section{Declarations}

\section{Ethics approval and consent to participate}

Ethical consent was provided by Department of Biology, University of Aveiro.

\section{Availability of data and material}


Data will be available upon reasonable request from the corresponding author.

\section{Funding}

No funding source available.

\section{Acknowledgements}

Authors would like to thank the CESAM-Centre for Environmental and Marine Studies, University of Aveiro for providing the zebrafish facility.

\section{Consent for publication}

Not applicable.

\section{Competing interests}

The authors declare that they have no competing interests.

\section{Author's Contributions}

Rita Pina and Luís Souto conceived of the study. Rita Pina developed all the experimental procedures, the analysis of the results and drafted the manuscript. Helena Moreira helps Rita Pina with the analysis of HRM results. All the authors participated in the revision of the paper and approved the final manuscript.

\section{Authors' information}

${ }^{1}$ Applied Genetics Laboratory, Department of Biology, University of Aveiro, Portugal. 
Rita Pina, Luís Souto \& Helena Moreira

Corresponding author

Correspondence to: Rita Sabino Abrantes de Pina (rita.sabino.pina@gmail.com)

\section{References}

[1] Maile, A. E., Inoue, C. G., Barksdale, L. E., e Carter, D. O. (2017). Toward a universal equation to estimate postmortem interval. Forensic Science International, 272, 150-153. https://doi.org/10.1002/cam4.22

[2] Cockle, D. L., Bell, L. S. (2015). Human decomposition and the reliability of a "Universal" model for post-mortem interval estimations. Forensic Science International, 253, 136-139.

https://doi.org/10.1016/j.forsciint.2015.05.018

[3] Li, W. C., Ma, K. J., Lv, Y. H., Zhang, P., Pan, H., Zhang, H., ... Chen, L. (2014). Postmortem interval determination using 18S-RNA and microRNA. Science and Justice, 54(4), 307-310.

https://doi.org/10.1016/j.scijus.2014.03.001

[4] Johnson, L. A., \& Ferris, J. A. J. (2002). Analysis of postmortem DNA degradation by single-cell gel electrophoresis. Forensic Science International, 126 (1), 43-47.

[5] Stefanova, P., Taseva, M., Georgieva, T., Gotcheva, V., e Angelov, A. (2013). A modified CTAB method for DNA extraction from soybean and meat products. Biotechnology and Biotechnological Equipment, 27 (3), 3803-3810. http://doi.org/10.5504/BBEQ.2013.0026

[6] Liu, Y., Zhang, Y., Tao, S., Guan, Y., Zhang, T., e Wang, Z. (2016). Global DNA methylation in gonads of adult zebrafish Danio rerio under bisphenol A exposure. Ecotoxicology and Environmental Safety, 130, 124-132. https://doi.org/10.1016/j.ecoenv.2016.04.012

[7]Bocklandt, S., Li, W., Sehel, M., Sánchez, F., Sinsheimer, J., Horvath, S., e Vilain, E. (2011). Epigenetic Predictor of Age. PLoS ONE, 6(6), 1434-1439. https://doi.org/10.1371/journal.pone.0014821

\section{Figures}




\section{Methylation content}

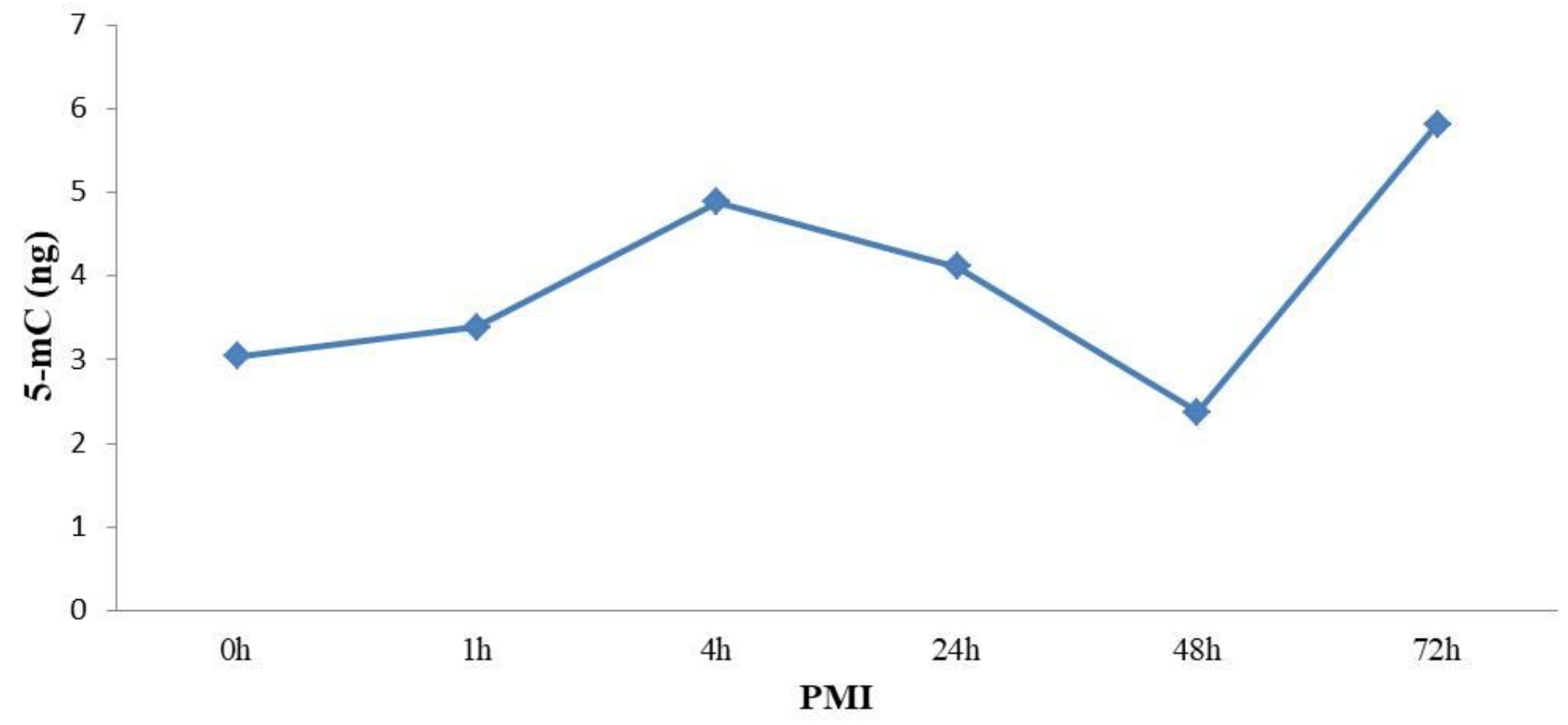

Figure 1

Variation in DNA Methylation levels during PMI

\section{Supplementary Files}

This is a list of supplementary files associated with this preprint. Click to download.

- AdditionalFiles.docx

- Table2alt.version.docx 